\title{
Who takes care of neurocritical patients in emergency departments? Exploration survey
}

Keywords: neurocritical patients, emergency department

\section{Background}

Acute neurological disorders imply a massive burden, being the third cause of death in the modern world, with elevated morbidity

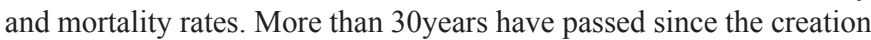
of neurological specialized intensive care units worldwide. The first text dedicated exclusively to this subject was published in $1983 .{ }^{1}$ Since then, education programs for neurocritical care physicians have been developed. These differ widely in their objectives and methods; nevertheless, there are hundreds of physicians exclusively dedicated to look after patients with this kind of disorders nowadays.

Howard et al., identified most of the pathologies that need to be treated in neurological intensive care units, but some issues were not really addressed, such as who should be in charge of these patients and when and why they should access these specialized areas. ${ }^{2}$

Having analyzed effectiveness, costs, and other results regarding the implementation of neurological intensive care units, many authors agree that the presence of an expert or a team of experts in these units improves outcomes. ${ }^{3-8}$ Particularly in our country, as in many others, there is an important issue still needed to be ruled out regarding the lack of intensivists. ${ }^{9}$ Likewise, cost-effectiveness and cost-usefulness of multidisciplinary teams specifically in charge of treating neurocritical patients has been broadly demonstrated. ${ }^{10-13}$

On the other hand, prehospital care and initial treatment of patients with acute neurological disorders in emergency departments have not seen the same rapid development and many issues still need to be reviewed and addressed properly. First hours remain crucial in treatment of patients undergoing acute neurological disorders, as risk can be categorized and care strategies executed in order to improve survival quality.

In the light of the current knowledge and irrespective of the reasons, we usually recognize that initial treatment is not always accurately provided in the emergency departments. The aim of this survey, therefore, is to explore who provides initial care, and takes responsibility for decisions regarding diagnosis and treatment of patients suffering from acute neurological disorders in emergency departments.

\section{Material and methods}

We designed an explorative web based survey that includes ten questions regarding hospital location and demographic characteristics, number of patients attending the emergency department daily, availability of specialized physicians and their contribution in diagnosis and treatment of neurological patients and transfer delay to specific healthcare areas, among others. All items had multiple choices or ordinal response formats, with only few questions concluding with 'other' option.

During April 2015, the questionnaire was sent by mail and available on the institutional website of Sociedad Argentina de Terapia Intensiva (SATI ${ }^{14}$ by its Spanish acronym). Physicians and emergency room staff members were invited to participate.
Volume 8 Issue 4 - 2018

\author{
Luis Camputaro,' Ana Kovac, ${ }^{2}$ Lucia Scalice, ${ }^{3}$ \\ Martin Steinhaus ${ }^{4}$ \\ 'Medical Director, Transplant Institute Buenos Aires City, \\ Argentina \\ ${ }^{2}$ Staff Physician, Emergency Medical Care System (S.A.M.E.), \\ Argentina \\ ${ }^{3}$ Staff Physician Intensive Care Department, Hospital Parmenio \\ Piñero, Argentina \\ ${ }^{4}$ Staff Physician, Intensive Care Department, Institute of \\ Oncology Ángel H,Argentina
}

Correspondence: Luis Camputaro, Medical Director,

Transplant Institute Buenos Aires City, Argentina,

Email luis.camputaro@gmail.com

Received: May |I, 2018 | Published: August 07, 2018

\section{Results}

\section{Study population}

109 responses were received. Each respondent did not answer all the questions; thus, the percentage of response for each question has been calculated accordingly. Of the 109 responses, 78\% (n=84) were from Argentina (Figure 1).

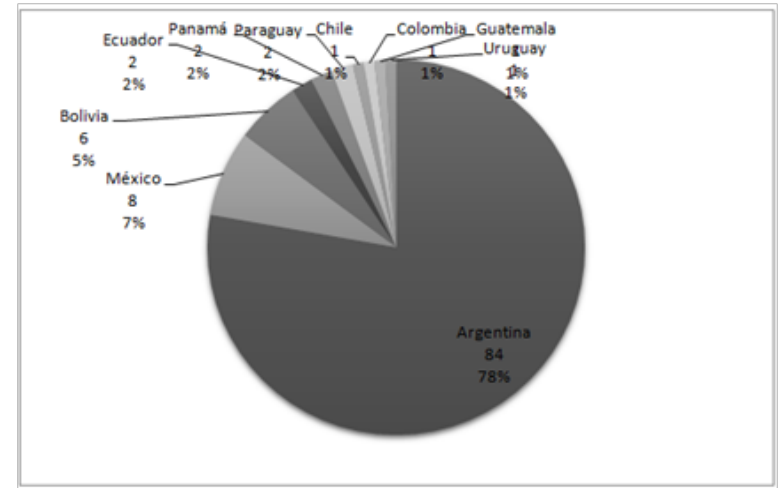

Figure I Responders categorized per country of origin $(n=\mid 08)$.

Among 109 responses, more than half $(58,3 \% ; n=63)$ of the respondents attend their practices in cities with over 300.000 inhabitants (Figure 2).

Regarding institutional characteristics, 37\% $(\mathrm{n}=40)$ provide more than 200 hospital beds (Figure 3), and mainly belong to public administration (national, state or government ownership) with low teaching hospital status rates, as denoted by university affiliations (Table 1).

In 103 responses, $83,5 \%(n=86)$ informed having less than $20 \%$ of its active staff certified as emergency physicians (Figure 4) and most 
neurology and neurosurgery consultants are either available on call or work only on a part-time basis (Table 2).

\begin{tabular}{|c|c|c|}
\hline$>1.000 .000$ & & $39 ; 36,1 \%$ \\
\hline $500.000-1.000 .000$ & $15 ; 13,8 \%$ & \\
\hline $400.001-500.000$ & $4 ; 3,7 \%$ & \\
\hline $350.001-400.000$ & $3 ; 2,7 \%$ & \\
\hline $300.001-350.000$ & $2 ; 1,8 \%$ & \\
\hline $250.001-300.000$ & $3 ; 2,7 \%$ & \\
\hline $200.001-250.000$ & $3 ; 2,7 \%$ & \\
\hline $150.001-200.000$ & $3 ; 2,7 \%$ & \\
\hline $100.001-150.000$ & $10 ; 9,2 \%$ & \\
\hline $50.001-100.000$ & $10 ; 9,2 \%$ & \\
\hline$<50.000$ & $16 ; 14,8 \%$ & \\
\hline
\end{tabular}

Figure 2 Responders practice location by city inhabitants $(n=108)$

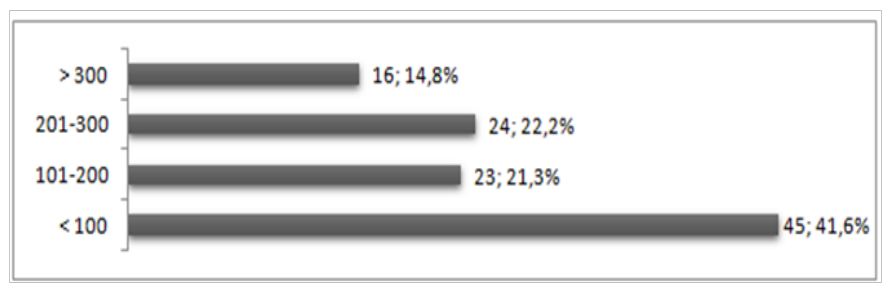

Figure 3 Healthcare centers by number of beds $(n=108)$.

\section{Emergency department activity data}

Almost half of the respondents $(49,1 \% ; n=53)$ assess more than
90 adult patients per day (Figure 5) and 69,2\% $(n=74)$ perceive that less than $20 \%$ of these patients have life threatening illnesses that require shock room admittance (Figure 6). Besides, they mostly agree that less than $10 \%$ of these critical patients suffer from neurological disorders (Figure 7)

\section{Who takes care of neurocritical patients?}

Half of the 106 responders $(50 \% ; n=53)$, replied that general practitioners are usually responsible for providing initial assessment of neurocritical patients in their practice. Only $25,5 \%(\mathrm{n}=27)$ responded that an emergency certified physician is available to provide initial care and in fewer occasions $(5,7 \% ; n=6)$ a neurologist is accountable (Figure 8).

Moreover, initial decisions about treatment are mainly made by a critical care physician, who is frequently the 'consultant' with more expertise on a 24 hour-basis (Table 3).

\section{Patient transfers}

After initial care, most neurocritical patients require either interfacility or intrahospital transfer for definitive treatment. However, patients may not reach their destination in a timely fashion. Our survey included two questions regarding this issue. Of 106 respondents, only $27 \%(\mathrm{n}=29)$ are always able to arrange an intrahospital transfer immediately and almost half of them $(47 \%$; $\mathrm{n}=50$ ) usually suffer delays of more than 2hours. Conditions are worse regarding interfacility transfers $(n=105)$, in which only $20 \%(n=21)$ can accomplish them within the first hours and 44,8\% $(n=47)$ account for more than 6-hour delay (Figure 9), (Figure 10).

Table I Healthcare centers characteristics regarding ownership and teaching hospital status (absolute values)

\begin{tabular}{lllll}
\hline Teaching hospital status & $\begin{array}{l}\text { No university } \\
\text { affiliation }\end{array}$ & $\begin{array}{l}\text { State university } \\
\text { affiliation }\end{array}$ & $\begin{array}{l}\text { Private university } \\
\text { affiliation }\end{array}$ \\
\hline Ownership & & & & $\mathrm{n}$ \\
Private/Proprietary & 30 & 6 & 6 & 42 \\
Community/Voluntary & 0 & 4 & 0 & 4 \\
Government (National) & 13 & 7 & 4 & 24 \\
Government (Provincial) & 24 & 9 & 0 & 33 \\
Government (Local) & 14 & 7 & 0 & 21 \\
\hline
\end{tabular}

Table 2 Specialist availability at emergency departments (absolute values)

\begin{tabular}{|c|c|c|c|c|c|}
\hline Medical specialist & Neurologist & Neurosurgeon & Anesthesiologist & Cardiologist & Infectious disease \\
\hline \multicolumn{6}{|c|}{ Type of employment } \\
\hline Full-time & 19 & 14 & 17 & 16 & 6 \\
\hline Part-time & 23 & 2 & I & 0 & 6 \\
\hline On call & 34 & 3 & 0 & 2 & 5 \\
\hline Not available & 21 & 0 & 0 & 0 & I \\
\hline
\end{tabular}

Table 3 Initial treatment decisions by specialist (absolute values)

\begin{tabular}{|c|c|c|c|c|c|c|c|}
\hline Medical specialty & $\begin{array}{l}\text { Emergency } \\
\text { medicine }\end{array}$ & Neurology & Neurosurgery & $\begin{array}{l}\text { General } \\
\text { practice }\end{array}$ & $\begin{array}{l}\text { Family } \\
\text { medicine }\end{array}$ & $\begin{array}{l}\text { Critical } \\
\text { care }\end{array}$ & Other \\
\hline \multicolumn{8}{|l|}{$\begin{array}{l}\text { Initial treatment } \\
\text { decisions }\end{array}$} \\
\hline Always & 1 & I & 1 & 2 & I & 6 & 0 \\
\hline 24 hours & 22 & 14 & 15 & 24 & 4 & 51 & 1 \\
\hline Depending on the case & 10 & 18 & 29 & 13 & 6 & 16 & 2 \\
\hline Depending on the timetable & 5 & 8 & 4 & 5 & 4 & 2 & 1 \\
\hline
\end{tabular}




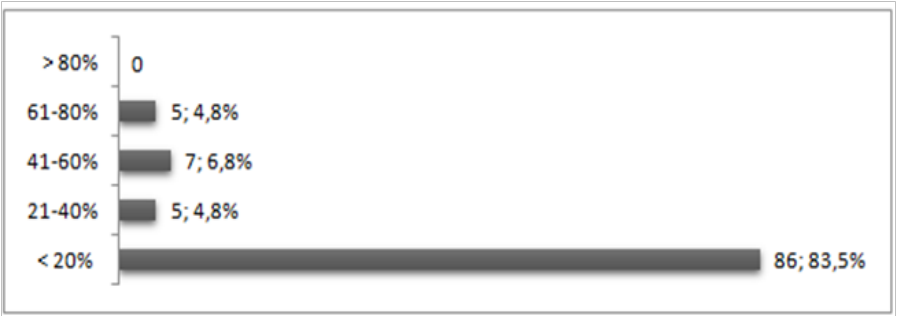

Figure 4 Percentage of active staff certified as emergency physicians $(n=103)$.

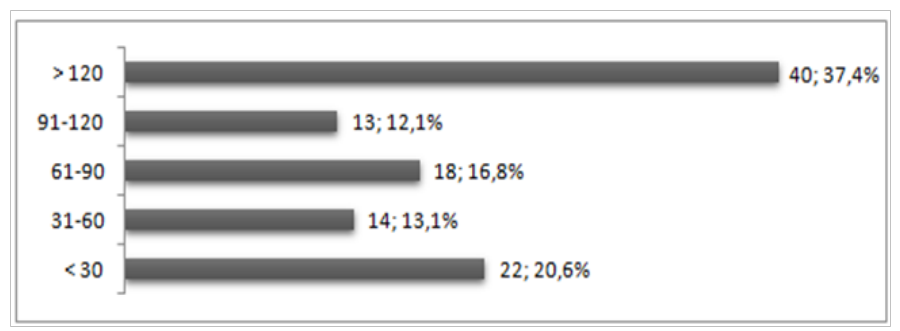

Figure 5 Number of adult patients assessed daily $(n=107)$

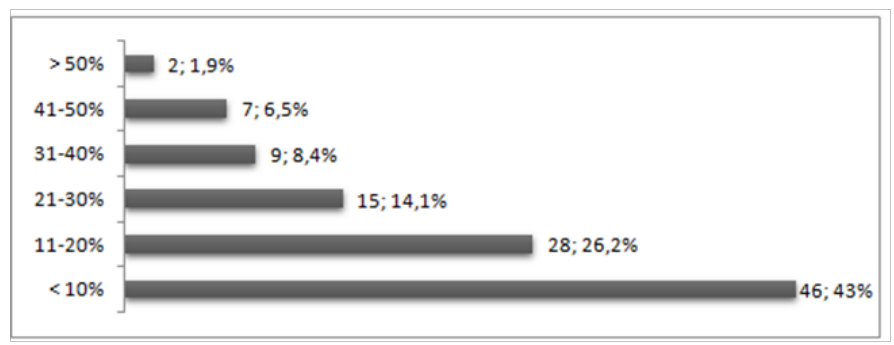

Figure 6 Percentage of adult patients who require shock room admittance $(n=107)$.

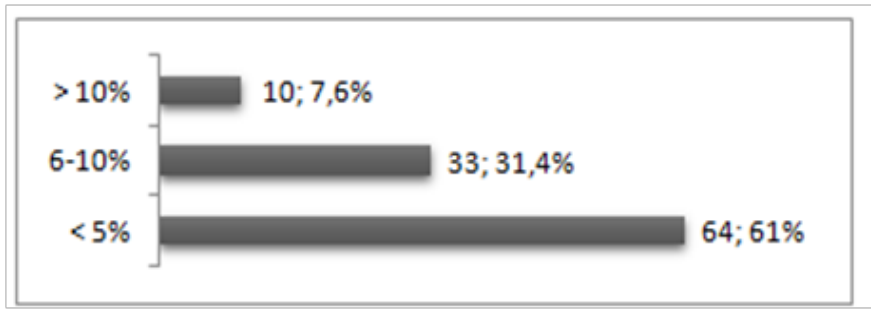

Figure 7 Percentage of neurocritical adult patients assessed daily $(n=105)$.

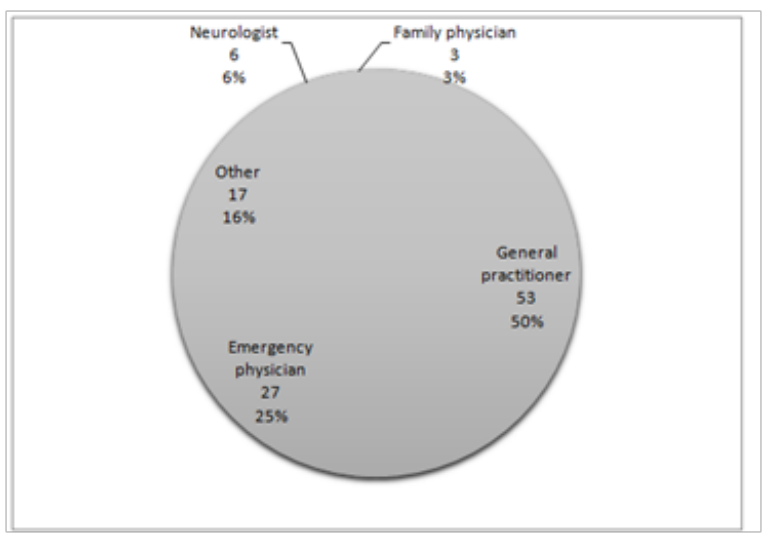

Figure 8 Initial assessment by specialist $(n=106)$.

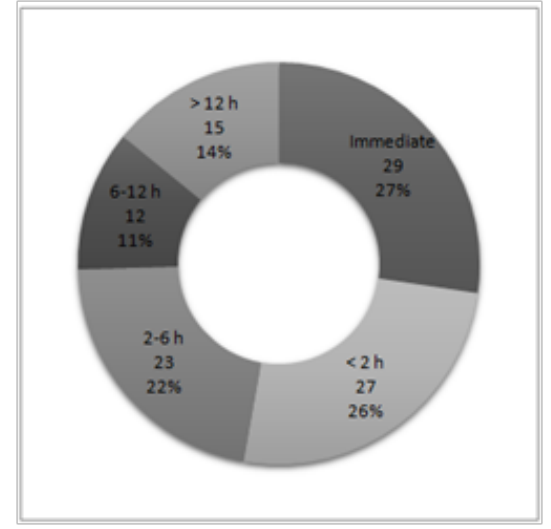

Figure 9 Intrahospital transfer delay $(n=106)$.

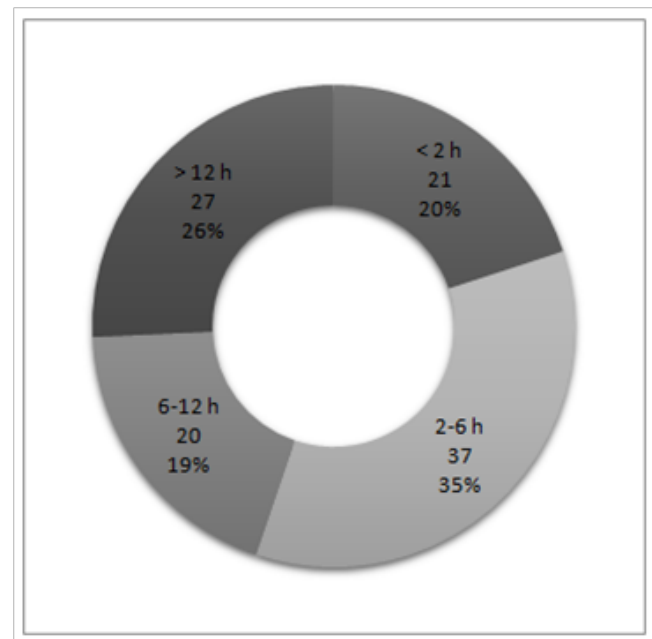

Figure 10 Interfacility transfer delay $(n=105)$.

\section{Discussion}

The aim of this survey was to explore who provides initial care, and takes responsibility for decisions regarding diagnosis and treatment of patients suffering from acute neurological disorders in emergency departments. To our knowledge, there are no previous reports in the literature on this specific scenario in Latin America.

Obtained responses mainly represent large urban hospitals' emergency departments, although most participants claimed that less than $20 \%$ of their active staff is certified as emergency physicians. While board certification is but one of several qualifications to be considered in assessing the quality of a physician's clinical care, it appears that such low rates of specialist care availability at reference centers should be a matter of concern.

Half of the survey respondents replied that general practitioners are usually responsible for providing initial assessment of neurocritical patients in their practice and initial decisions regarding treatment are mainly made by critical care physicians, and rarely by a Neurosurgeon or Neurologist. The current literature supports a beneficial relationship between the presences of a specialized critical care team (staffed by a neurointensivist) and enhanced patient outcomes. ${ }^{7,8}$ Therefore, there is a need to recognize the lack of knowledge and support further training for medical staff attending emergency departments, especially on the subject of neurocritical patients' acute care. 
We also found out that hospital emergency departments, regardless of the reason, perform fairly poorly in transferring acutely ill patients within a reasonable time frame. Several reports suggest that the problem is widespread and contributes significantly to inefficiencies in healthcare systems; hence further study of this problem is necessary.

The strength of our study is that it reveals the ongoing practice of surveyed physicians regarding attention of neurocritical patients. It is the first of a kind, exploratory survey and includes responses from health professionals, who are involved in the management of patients with acute neurological disorders in Latin America. Limitations of our study include a restricted generalizability of our results due to a nonrandom sampling method used for our survey and limited access to physicians contact databases, leading to restricted survey distribution and inability to introduce a survey to larger national and international population (especially outside Argentina). Despite these caveats, the authors believe the data to be an accurate reflection of current practice in Latin America.

\section{Conclusion}

Most of the surveyed participants claim that neurocritical patients in emergency departments are initially assessed by general practitioners and initial decisions regarding treatment are mainly made by critical care physicians. Patient transfer for definitive treatment is often delayed.

The authors recognize the need for, and welcome, further examination of these findings from multiple perspectives and despite the limitations of this survey conclude that further education and training of emergency department physicians, especially those taking care of patients with acute neurological diseases should be encouraged. This survey and its conclusions also include a kindly recommendation for health systems authorities that wish to improve effectiveness when making decisions to invest in neurocritical care.

\section{Acknowledgements}

None.

\section{Conflict of interest}

The author declares no conflict of interest.

\section{References}

1. Ropper AH, Kennedy SK, Zervas NT. Neurological and Neurosurgical Intensive Care. Baltimore: University Park Press; 1983.

2. Howard R, Kullmann D, Hirsch N. Admission to neurological intensive care: who, when, and why? J Neurol Neurosurg Psychiatry. 2003;74(Suppl 3):iii2-iii9.

3. Diringer MN, Edwards DF. Admission to a neurologic/neurosurgical intensive care unit is associated with reduced mortality rate after intracerebral hemorrhage. Crit Care Med. 2001;29(3):635-640.

4. Elf K, Nilsson P, Enblad P. Outcome after traumatic brain injury improved by an organized secondary insult program and standardized neurointensive care. Crit Care Med. 2002;30(9):2129-2134.

5. Mirski MA, Chang CW, Cowan R. Impact of a neuroscience intensive care unit on neurosurgical patient outcomes and cost of care: evidencebased support for an intensivist-directed specialty ICU model of care. $J$ Neurosurg Anesthesiol. 2001;13(2):83-92.

6. Patel HC, Menon DK, Tebbs S, et al. Specialist neurocritical care and outcome from head injury. Intensive Care Med. 2002;28(5):547-553.

7. Suarez JI, Zaidat OO, Suri MF, et al. Length of stay and mortality in neurocritically ill patients: impact of a specialized neurocritical care team. Crit Care Med. 2005;32(11):2311-2317.

8. Varelas PN, Eastwood D, Yun HJ, et al. Impact of a Neurointensivist on outcomes in patients with head trauma treated in a neurosciences intensive care unit. J Neurosurg. 2006;104(5):713-719.

9. Krell K. Critical care workforce. Crit Care Med. 2008;36(4):1350-1353.

10. Chang CW, Torbey MT, Diringer MN, et al. Neurointensivists: part of the problem or part of the solution? Letters to the Editor. Crit Care Med. 2008;36(10):2963-2964.

11. De Silva DA, Copenhaver BR, Burgess RE, et al. On our way to evidencebased medicine: impact of a neurointensive team on stroke outcomes. Neurocrit Care. 2008;9(3):285-286.

12. Bershad EM, Feen ES, Hernandez OH, et al. Impact of a specialized neurointensive care team on outcomes of critically ill acute ischemic stroke patients. Neurocrit Care. 2008;9(3):287-292.

13. Varelas PN, Schultz L, Conti M, et al. The impact of a neuro-intensivist on patients with stroke admitted to a neurosciences intensive care unit. Neurocrit Care. 2008;9(3):293-299.

14. www.sati.org.ar 